\title{
LA DIETA HUMANA EN EL PLEISTOCENO
}

\author{
La diète humaine dans le Pléistocene
}

\author{
José Manuel Gómez-Tabanera*
}

Recibido el 2 de octubre de 2007. Aceptado el 8 de noviembre de 2007.

\begin{abstract}
Resumen. A lo largo de la historia de la humanidad, los hábitos alimentarios han cambiado sustancialmente. En el presente texto se abordan algunos tópicos que se han manejado ampliamente y se discute su idoneidad. Palabras clave: Dieta humana. Endocrinología. Prehistoria.
\end{abstract}

Résumé. Tout au long de l'histoire de l'humanité les habitudes alimentaires ont beaucoup changé. Dans ce texte ont aborde certains sujets qui ont été largement utilisées et traite de son aptitude interpretative. Mots-clés: Diète humaine. Endocrirnologie. Préhistorie

\section{INTRODUCCIÓN}

El título de las presentes páginas que quiero dedicar al paleolitista y finado amigo Prof. Dr. Eduardo Ripoll Perelló obedece a una preocupación que, desde años, como antropólogo y prehistoriador, me embarga a la hora de intuir cuál era el sustento habitual/cotidiano del hombre del Paleolítico, incluyendo en tal acepción a aquellos antecesores de la especie humana que hemos venido conociendo desde, pongamos por caso, el ser que dio nombre al hoy conocido como Homo habilis, dando nombre a tipos sucesivos como el Homo ergaster, precursor del $H$. erectus, que emergió en nuestro Planeta desde, quizás, un millón de años antes del presente. Un homínido que, ya a mediados del siglo XIX, accedimos a denominar vagamente pre-neanderthalensis ${ }^{1}$, al desconocer su presunta taxonomía evolutiva, anterior al $H$. neanderthalensis, localizado en Alemania y que dio nombre al especimen, aún cuando sus restos fósiles fueron ya conocidos desde años anteriores (1848) en el Peñón de Gibraltar (España) y en Engis (Bélgica).

Hace más de un cuarto de siglo toqué un tema bajo el título general "Cocinar hizo al hombre", en una aportación des- tinada a una publicación universitaria que ignoro fuese publicada, ya que, en su día, no recibí ni un número ni separatas de la misma. Recuerdo, sin embargo, que en el mismo sostenía que los primeros homínidos empezaron a cocinar/guisar sus pitanzas tras la conquista del fuego, que remontaba a un mínimo de medio millón de años, según los vestigios que la arqueología prehistórica mostraba junto al entonces, quizás, mar interior del Rift (África Oriental), no lejos de Kenya, pero también en Pekín, China. El afirmar entonces tal cosa suponía dar por descontadas otras. Así, que un primate, tenido por vegetariano, se había tornado en omnívoro, lo que le hizo, por fuerza y ante el medio circundante, carroñero y depredador pero, a la vez, inventor de los primeros "útiles" líticos que los tipólogos paleolitistas vienen denominando "módulo A", sin hablar de otros materiales, lo que suponía que se otorgaba al primate en cuestión un mínimo proceso de raciocinio que, merced a la evolución, le supondría la conquista de una primera inteligencia y con ello, la emergencia de un hijo que superaba a la famosa $L u c y^{2}$, al acceder al lenguaje articulado. Recuerdo también que en el artículo traspapelado, al discurrir sobre el dominio del fuego me cuestionaba cómo éste podia ser producido por su mismo usuario

(*) Universidad de Oviedo. M. C. de la R.A.H. (Madrid). Bellas Artes y Ciencias Morales y Politicas (Madrid).

(1) Actualmente las nuevas taxonomías han prescindido de dicha denominación, ya que, en principio, se refieren al tipo ya denominado H. erectus, que se considera, en cierto modo, coetáneo al H. Heidelbergensis o al H. antecessor de Atapuerca (Burgos).

(2) Sobre la misma existe numerosa bibliografía en castellano, tanto monografías como manuales. Recomendamos, no obstante, el libro colectivo "Antes de Lucy", (Coord. J. Agusti). Barcelona, Tusquets Editores (Metatemas), 2000. Se recuerda que Lucy fue el mote dado a un primate fósil sugerido por las iniciales de una célebre tonada de moda de los Beatles, canturreada diariamente por los propios arqueólogos, aún cuando en la taxonomía figure bajo el nombre de Australopithecus afarensis. 
y conservado en los vivacs (hogares) de sus acampadas, aunque no acierto a recordar cómo solucioné la cuestión, posiblemente deduciendo que este primer primate destinado a convertirse en el primer cocinero humano, más que primer Prometeo, aprovechó el rescoldo de algún incendio natural conservándole encendido para sus fines, que irian desde el calentamiento hasta su utilización para alterar molecularmente los presuntos alimentos a utilizar, desde pitanzas cárnicas a frutos, artrópodos, reptiles, anélidos y sabandijas varias, a las que su cocinado hizo más apetecibles. Quiero recordar también que en mi elucubración tuve en cuenta algo que ya sabía por el P. Barandiarán, de viejos usos euskaldunas, utilizando guijarros y piedras candentes para calentar la leche, según una tradición milenaria, que les permitía disponer de potajes y brebajes calientes, utilizando para su ejecución, en un primer momento, sacos de pieles de sus presas, dado que todavía habrian de transcurrir miles de años para que fuera inventada la cerámica, ya en el Neolítico. No recuerdo si descarté, por otra parte, que en alguna ocasión el hombre pleistocénico pudiera utilizar el termalismo natural de algunas aguas, al igual que hizo ya en épocas históricas.

\section{ANTE LA LLAMADA "DIETA PALEOLÍTICA"}

Hilvanando todas estas ideas quizá pueda escribir algo que pueda interesar sobre la que llamariamos "dieta paleolítica", idea ésta que lleva barajando desde hace varios lustros, el profesor Staffan Lindeberg, de la Universidad de Lund (Suecia), quien se vio atraído por el tema al observar las poblaciones indígenas de Kitava, Islas Trobiand (Papúa, Nueva Guinea) ${ }^{3}$, llevando a cabo puntualizaciones varias de gran interés para la patología humana, con referencia a síndromes cardiovasculares y diabetes. De esta forma, Lindeberg pudo establecer que, al igual que hoy se habla de dieta mediterránea, puede hablarse de dieta atlántica y, a la vez, de dieta paleolítica, reservando tal denominación para una dieta harto utilizada, ya por el hombre paleolítico, ya de los orígenes, cuyo patrón no permitía, como hoy, la existencia de gentes obesas, lo que constituyó un peligro para su misma humanidad que, por entonces, no sabía de otros recetarios médicos que aquellos que le dictaba la experiencia de sus mayores, no imaginando que un tercio de las muertes prematuras podrian estar irremisiblemente asociadas a la dieta, ni siquiera si podian tornarse obesas o no, cosa que, naturalmente, quizá no era posible con la llamada dieta paleolítica, que realmente ignoramos en qué consistía, aunque queda claro que se imponía muchas veces en las hambrunas que pudo pasar el hombre paleolítico que, en diferentes ocasiones, se vio forzado a la antropofagia (canibalismo) como última solución ${ }^{4}$. A este respecto, los restos encontrados hace más de un trienio en la cueva de Atapuerca (Burgos, España) y asimismo hace años en Kaprina (Croacia) no dejan lugar a dudas, tanto más cuando proceden de neanderthales sin experiencia religiosa conocida, que pudiera quizás explicar tal comensalismo, que hoy consideramos contra natura, aunque nos recuerde un tanto el sacramento de la Comunión practicado por los católicos, cuando pretenden ingerir el cuerpo de un presunto Dios-hijo que, en realidad, es un trozo de pan ázimo, utilizado ritualmente. Naturalmente, el canibalismo humano ha existido siempre entre distintos pueblos, incluso civilizados. Recuérdese que fue utilizado como subsistencia tras un accidente aéreo en los Andes, por los supervivientes.

Subrayando el uso del fuego, existe bien documentado desde 700.000 B.P. en Azerbaiján (Achelense antiguo), pero también hace unos 350.000 en Vértessöllös (Hungría), Hachenheim III (Alsacia), Lunel Biel (Hérault, Francia), Terra Amata (Niza), Arago, los tres hogares de Bilzingslebel (Alemania), los presuntos hogares de Torralba y Ambrona (Soria, España), Orgnac III, Cagny, Grotte d'Éscaele, Saint Vallien, Biache Saint-Vaast (Francia), Pontnewidd (País de Gales), etc., todos ellos vinculados a la primera presencia humana en Europa. Aún de fecha reciente es el hallazgo en Nolhac-Biard (Alto Loira) de un lugar fechado entre 1.200.000-1.800.000 millones de años, en los que se detectó un presunto hogar, quizás uno de los primeros que prueba el uso del fuego controlado en Europa. En Asia está el Locus 13 de Zhukudian (China), considerado hasta hace poco harto antiguo, aunque no pueda probarse su intencionalidad. Con todos estos topónimos recordamos lugares de habitación que, desde sus orígenes, preocuparon al hombre a la hora de vivir en grupos, aumentando su seguridad, organizando la explotación del medio y satisfaciendo sus necesidades sociales. Henos asi ante un lugar adecuado, en el que enseguida desarrolló unas técnicas de acondicionamiento que sentarían las bases de una tecnología del hábitat en la que muy pronto se utilizaron materias primas y manualidades singulares. El más antiguo lugar de este tipo lo constituyó FLK NNI de Olduvai (Tanzania), a datar circa 1.800 .000 años B.P., donde se descubrió un conjunto de piedras constituyendo un semicírculo, interpretado como un protector contra el viento, haciendo realidad la primera "obra" de construcción humana conocida.

Por otra parte, se ha constituido en lugar común el creer que el hombre del Paleolítico inferior sólo utilizaba las cuevas como viviendas, pese a que la investigación arqueológica

(3) Dicho islario fue estudiado detalladamente por el antropólogo polaco Bronislaw Malinowski (1884-1942) quien formado en Gran Bretaña llevaría a cabo diversas misiones en Melanesia, particularmente en las islas Trobiand, que le dieron fama universal. Para su biografía, cf. Diccionario Akal de Etnologia y Antropología (Coord. P. Bonte y M. Izard). Trad. esp. Madrid Akal, 2005 (págs. 452-454).

(4) Actualmente existen serias divergencias a la hora de interpretar el canibalismo como solución alimentaria en algunos pueblos primitivos actuales, por lo que la antropofagia prehistórica se considera de acuerdo con el yacimiento en que se presente, aunque no se descarta que existiese en el Asia Neanderthalensis. 
hace pensar en cierta variedad de hábitats: cuevas permanentes o temporales, estructuras al aire libre $y$, a veces, cabañas en el interior de las cuevas (más concretamente en el vestíbulo), que permitían asi tener un doble techado en lugar de habitación. Hoy alguna de estas cuevas, naturalmente, no se conservan como entonces; así, en la Costa Azul se han localizado cuevas hoy submarinas con extraordinarias pinturas rupestres y que fueron otros tantos refugios terrenos del hombre paleolítico. También se ha accedido a antros como la cueva Chauvet (Vallón Pont-d'Arc. Ardeche, Francia) con fauna de especies no habituales, como rinocerontes y felinos y cuya presencia no ha sido totalmente explicada aún por los especialistas, incluso apelando a los estudios estadísticos del finado A. Leroi Gourhan, aún cuando, aqui como en otras cuevas, presentan un particular orden de distribución, de forma que el panel se presenta un tanto equilibrado en su ejecución, cual si fuera un espacio ritual o sagrado, reservado para la imágenes evocadas. Todo ello es evidente que puede darnos noticias de la organización interna de los grupos y del perfeccionamiento de las estrategias de abastecimiento y caza, casi siempre supeditadas al clima reinante. No es de extrañar que algunos especialistas, que además de arqueólogos son endocrinólogos, hayan desarrollado teorías y explicaciones como la "teoría lipostática", intentando explicar los factores biológicos que controlan el hipotético monitor del contenido en grasa corporal de los individuos que integran un grupo. Así es obvio que la reserva de grasa al descender por debajo de un determinado límite, sea detectado por tal monitor que estimula el hambre, permitiendo que aumente la ingestión de alimentos y, a la vez, inhibe la reproducción hasta que el peso graso se recupere. Hoy los especialistas saben de tal mecanismo. Una de las claves, a parte de la misma insulina y otros factores, es la hormona que produce en las células del tejido adiposo la llamada leptina, que procede según detallamos.

Así, nos encontramos con un frío intensísimo que impide a los miembros de un grupo o clan abandonar su refugio durante semanas y salir a cazar. Sin nada que comer, consumen todas sus reservas de grasa y su tejido adiposo se reduce de tamaño. Cuando las células adiposas pierden grasa, dejan de liberar la hormona leptina, lo que es captado por el cerebro activando el hipotálamo, zona que, entre otras funciones, controla el hambre. En ausencia de leptina el hipotálamo desencadena la sensación de hambre (ihay que llenar los estómagos!). Sin embargo, los homínidos famélicos, apenas sin fuerzas, siguen sin abandonar su refugio por causas meteorológicas o climáticas. Al persistir la situación, merced a mecanismos hoy bien conocidos, reduce la sensación de las gonadotrofinas LH y FSH, encargadas de controlar la función de las gónadas. El descenso de estas hormonas provoca un freno en la actividad del ovario y se produce la amenorrea y la anovulación, lo que ocasiona esterilidad en esa hembra ${ }^{6}$.

Al aminorarse el intenso frío puede salirse a cazar e incluso capturar, pongamos por caso, un reno, transportándole al refugio $y$, durante una semana, se atracarian con su carne y con su grasa. La hembra hambrienta comenzaba a rellenar rápidamente sus depósitos de grasa (a lo que contribuye, como ya sabemos, la insulinorresistencia) y al crecer el tamaño de sus células grises se estimulaba la secreción de leptina, lo que se sabe por una oportuna señal al hipotálamo que inhibe ya del hambre. En el caso de leptinorresistencia, el hambre no se aplaca tan fácilmente, por lo que los homínidos seguirán comiendo hasta atiborrar sus adipocitos con la grasa acumulada. No obstante, bajo la influencia de la leptina, el hipotálamo volvería a activar la secreción hipofisaria de gonadotrofinas LH y FSH y estas hormonas activarian nuevamente el ciclo ovárico y la hembra volvía a ser fértil.

Esta explicación de la grasa de la hembra y la supervivencia del grupo de presuntos antecesores, tiene una importancia capital que parece demostrarse con la presencia de numerosas estatuillas paleolíticas de presuntas diosas de la fecundidad, en concretos lugares de Eurasia, a datar 35.000 años B. P., representando siluetas de mujeres más bien obesas. Evidencia que quizá confirma la teoría.

Llegados a este punto, siguiendo los razonamientos de J. E. Campillo, volvemos al mitologema de Prometeo, eso es, el homínido, más o menos mítico, que supo domesticar el fuego utilizándole para el cocinado/guisado de los alimentos. En páginas anteriores hemos enumerado una serie de hogares permanentes y el dominio del fuego parece poder ser atribuido, ya a un $H$. ergaster, a un preneanderthalense, o ya al hombre de Atapuerca, aunque no hubiera llegado a sapiens. Recuerdo, cuando hace un cuarto de siglo visité, un tanto alucinado, Terra Amata, en la Costa Azul francesa, donde H. de Lumney decia haberse topado con unas primeras evidencias europeas. El descubrimiento fue objeto de un posterior congreso internacional y dio bastante que hablar al encontrarse también coprolitos (heces fósiles) integrados por granos de arena, carbón vegetal, fragmentos de conchas y moluscos, etc. Al parecer, se daba por supuesto que arena y conchas podian explicar su presencia por la proximidad de la playa, donde se encontró el yacimiento, dejando pensar que los restos de carbón del yacimiento frente a la playa denunciaban que se cocinaba la comida antes de consumirla. Parece fuera de duda que las conchas se introducian cerradas entre las cenizas. Algo parecido se presenta en los restos de moluscos, crustáceos y pescados que aparecen con signos de haber sido cocinados en las cuevas de la costa del mar interior que ocupaba el Rift del este africano ya recordado, aún cuando la datación de los mismos mediante $\mathrm{C}^{14}$ nos den la

(5) Cf. al respecto Campillo Álvarez J. E. "El Mono Obeso", Barcelona, Crítica, 2005 (3a edición). Página 172 y ss.

(6) Cf. Campillo Álvarez J. E. Loc. cit. pág. 174. 
mitad de antigüedad que en la Costa Azul. Todo ésto nos hace cavilar y volver a cosas elucubradas docenas de años atrás, cuando un tanto ingenuamente pensamos que los primeros asados pudieron ser casuales, frutos de algún incendio en la jungla, que dejó cadáveres chamuscados de diversa fauna. Pensamos incluso que al saborear estos restos, nuestros antepasados primates, aún no humanos, descubrieron que la pitanza que se presentaba más blanda y más fácil de desgajar o masticar con sus mandíbulas. Henos así ante el primer "cocinado", harto simple, reducido a simples asados, dado que las técnicas de hervido en agua o en aceite (frituras) suponian la utilización de recipientes ad hoc que, por lo que sabemos, sólo pudieron inventarse en el Neolítico, ya en el Holoceno, por el Hombre de Cro-Magnon o sucesores, a quienes pudo ocurrirsele colocar sobre sus hogares toscos recipientes de pieles (¿cosidos?), no contentándose quizá con ahumar los restos de sus cacerías o carroñas, con objeto que durasen más tiempo sin descomponerse?.

De aquí que pueda pensarse que el dominio del fuego y su utilización para el tratamiento de alimentos estimuló, tanto en el Hombre de Neanderthal como en el Hombre de Cro-Magnon, una mayor encefalización que permitió reducir, más si cabe, el tamaño de su aparato digestivo. Sabemos de autores que achacan también a ésto el crecimiento final de nuestro volumen cerebral al que llegó la especie humana, incorporándole a su evolución. El caso es que el cocinado de alimentos animales y vegetales, que posiblemente se inicia hace unos 300.000 años B.P., constituyó una auténtica revolución en la alimentación humana. No tardó el Homo sapiens en darse cuenta de tal avance, aprovechado incluso por sus propios expertos -entre los que incluimos a los chamanes 0 médicos-brujos de su grupo-. Sin embargo, quizá no llegaron a percibir que el cocinado neutralizaba muchas toxinas, -aún no se habian definido-, contenidas en legumbres y en farináceos, como la mandioca, la yuca y el ñame -hoy frutos del Trópico-, permitiendo disponer de nuevas fuentes alimentarias. Tampoco, que los alimentos cocinados/guisados aumentaban en digestibilidad, logrando que la alimentación fuera de mayor calidad nutricional, al requerir menos trabajo digestivo para extraer los nutrientes y la energía de los alimentos tratados. De aquí que el cocinado de los alimentos constituya una solución tecnológica, al igual que muchas ya anticipadas por el novelista Aldous Huxley ${ }^{8}$, que permitieron que parte del proceso digestivo tuviera lugar fuera del cuerpo, logrando así una digestión metabólicamente más económica, utilizando un aparato digestivo de menos volumen.

\section{DIETA PALEOLIITICA Y ENDOCRINOLOGÍA}

Hemos tenido ocasión ya de recordar al endocrinólogo J. E. Campillo, impuesto en Paleontología humana. Campillo, en su libro"El mono obeso", se remonta en su conocimiento de la especie humana al Homo ergaster, presunto sucesor del Homo habilis y predecesor del Homo erectus, quizás el primero en expandirse por Eurasia tras abandonar el continente africano ${ }^{9}$, manifestándose en la península Ibérica como Homo antecessor (Atapuerca); en Alemania como Homo heidelbergensis; en el Cáucaso (Dmanisi) como Homo georgicus, en China como Hombre de Pekín; en Indonesia como Hombre de Java, etc. Homínidos de los que hoy sabemos que precedieron al $H$. neanderthalensis, que incluso llegó a vivir hasta 30.000 años B.P., sucumbiendo ante una nueva especie, el Homo sapiens sapiens, localizado tempranamente en Cromagnon (Les Eyzies, Francia), posiblemente nuestro auténtico progenitor, con un cerebro bastante complejo y a quien sus perfomances permitieron, tras más de 100.000 años de glaciación (Würm), sobrevivir en un paisaje periglaciar, invadido por la tundra y la taiga, propicia ésta a florestas caducifolias (robles, hayas, encinares, alisos, avellanos, encinares, fresnos, etc.).

La Prehistoria, que empezaría a configurarse hace siglo y medio, conoce ya bastante de este último taxón humano que, desde luego, superaba en fortaleza al actual, quien, por lo general, desciende en un 17\% en la fuerza muscular del Hombre de Cromagnon, ajeno a la insulinorresistencia del hombre actual (Homo sapiens sapiens), potenciada mayormente en las hembras, muchas de ellas sometidas a la llamada diabetes gestacional, quien orientó su metabolismo para conservar la glucosa necesaria, no sólo para su supervivencia, sino para la producción láctea destinada a la prole, adoptando una conformación abdominal en forma de pera, que encontramos realzada en esas estatuillas paleolíticas, un tanto ampulosas, que se estudian en el arte mueble paleolítico y que por sí solas manifiestan una gloriosa maternidad.

Guiándonos por Campillo Álvarez, se puede incluso hablar de la hambruna paleolítica como anticonceptivo y pensar que, en ocasiones y en las bandas paleolíticas, las mujeres con bajo porcentaje de grasa corporal (aprox. un 10\% de su peso) presentaban un adelgazamiento extremo - por no hablar de anorexia-, el mismo que se observa en otras figurillas femeninas del arte mueble paleolítico y que les producía una inhibición de la ovulación y una amenorrea -al igual

(7) Investigaciones recientes parecen dar por sentado que las primeras agujas de coser fueron inventadas en Kostienski (Rusia), unos 50.000 años B.P.

(8) Aldous L. Huxley (1894-1963) fue un escritor británico, nieto del célebre naturalista R. H. Huxley (1825-1895), convertido al darwinismo. Aquí nos referimos a alguna de las tesis planteadas por Aldous Huxley en su célebre novela "Brave New World" (1932), pergeñada en la tradición futurista de Wells y de Orwell.

(9) Cf. al respecto mi comunicación al VIII Congreso Internacional de Caminería Hispánica: "La Diáspora Caminera de los Primeros Homínidos sobre el planeta Tierra". Madrid. Pastrana 2006. Actas en impresión, aunque se ha publicado ya separata íntegra de la comunicación (Oviedo. Imp. Gofer, 2006). 
que hoy-, lo que en el Paleolítico venía a equipararse con "hambruna". Henos ante una situación que ha cambiado en los últimos 10.000 años B. P., pongamos por caso, y cuyo estudio ha dado lugar incluso a numerosos planes de alimentación, como la caveman diet, o la ya citada paleolithic diet que incluso han merecido ser estudiadas con cierto detalle en Internet. Estudios que han permitido adaptar tales dietas a épocas nutricionales de nuestra evolución, incluso evitando la obesidad a la que han sucumbido numerosos pueblos del llamado Primer Mundo, lo que jamás ocurrió cuando la especie humana se limitaba al Ardipithecus ramidus, a Lucy, e incluso, a su presunto sucesor, el Homo habilis.

Sondeando el pasado y teniendo en cuenta el llamado Índice de Masa Corporal (IMC) en que cabe reducir el peso del Homo sapiens actual, dividiendo su peso en kilogramos; por su talla, en metros y elevado al cuadrado, pude llegarse a una solución, teniendo en cuenta que un 50\% de la alimentación del Homo sapiens debe ser como la del Ardipithecus ramidus; un 30\% como la del Australopithecus affarensis; un $18 \%$ como la del Homo ergaster y un $2 \%$ la que llegó a conocer el Homo sapiens (Cro-Magnon). De esta forma puede mantenerse perfectamente la especie vigente, tanto más cuando sus necesidades de alimentos se presentan unidas al gasto energético (movimiento), aún cuando éste dependa, o no, del trabajo muscular. En realidad nos enfrentamos a la evidencia de que el cuerpo del Homo sapiens actual está sometido a las leyes de la termodinámica, opinen lo que opinen los inventores de remedios maravillosos para adelgazar. Para tal deducción hay que tener siempre en cuenta que los requerimientos de ingestión de energía en el habitante de la sociedad industrial, vienen a ser de unas $32.000 \mathrm{Kcal} / \mathrm{Kg}$ de peso/día, mientras que en el Hombre de Cro-Magnon y en los pueblos primitivos actuales (cazadores/recolectores) viene a ser de unos $50 \mathrm{Kcal} / \mathrm{Kg}$ de peso/día.

Independientemente, hay que considerar el llamado estrés y sus consecuencias, que se produce ante situaciones de emergencia desencadenadas por las respuestas metabólicas y cardiovasculares típicas del estrés, que sobreviene cuando menos se piensa, activando el sistema simpático, con la natural producción mayor de adrenalina y de la noradrenalina que acelera el corazón, aumentando la presión arterial para permitir que circule más sangre por los músculos y así salvaguardar la existencia. Sin embargo, si no nos movemos y esta descarga se reitera día a día, acabará produciéndose una hipertrofia cardiaca y una hipertensión arterial.

Indudablemente la existencia humana ha cambiado, más en el llamado Primer Mundo, volcado en el sedentarismo y, con el mismo, el estrés al que habría que responder con los dos grandes sistemas de comunicación de que disponemos (el nervioso y el endocrino), a través del denominado sistema hipotálamo-hipofiso suprarrenal (HHS), cuya descripción nos llevaría aquí a derivaciones imprevistas en este momento, al constituir "un pozo sin fondo, o un mar de vaivenes arrítmicos, en cuyo espejo nos podemos reflejar para reconocernos", como hace unos pocos días subrayó M. Álvarez-Uría en su Lección Inaugural del Curso de la Universidad de Oviedo (2007-2008) ${ }^{10}$, dándonos claro pretexto para terminar la presente comunicación, más, cuando el profundizar en tal tema nos alejaría del contenido concreto de la misma.

$\left.{ }^{10}\right)$ El texto del mismo ha sido recientemente publicado por la propia Universidad de Oviedo. 